\title{
Characterization of Impact Toughness Properties of DIN39MnCrB6-2 Steel Grade
}

\author{
João Paulo Gomes Antunes ${ }^{a}$, Carlos Angelo Nunes ${ }^{a}$ \\ ${ }^{a}$ Escola de Engenharia de Lorena (EEL), Universidade de São Paulo (USP), Estrada Municipal do \\ Campinho, s/n, 12602-810, Lorena, São Paulo, Brazil.
}

Received: March 30, 2017; Revised: October 27, 2017; Accepted: October 29, 2017

\begin{abstract}
Boron added steels in quenched and tempered condition have been widely used in applications where good mechanical properties and low cost are required. In this study, impact resistance of DIN $39 \mathrm{MnCrB6}-2$ steel grade was investigated due to its criticality in automotive components. Metastable phase diagrams were built to guide heat treatments. The influence heat treatment parameters and initial microstructure were evaluated. Impact toughness results showed low absorbed energy $(<30 \mathrm{~J})$ for all tempering temperatures. CVN impact toughness was substantially increased in samples submitted to solution treatment. Microscopic observation showed coarse borocarbides in surface fracture of Q\&T samples. It was concluded that the formation of borocarbides is inherent in boron steels and their coarse morphology should be avoided in order to reduce embrittlement.
\end{abstract}

Keywords: boron steel, hardenability, borocarbide, $\mathrm{Fe}_{23}(B, C)_{6}$

\section{Introduction}

Since early studies in 1907 , boron addition has been widely used to improve steel hardenability with low cost and has played a key role in development of quenched and tempered (Q\&T) high strength steels. ${ }^{1 ; 2}$

The occurrence of borocarbide $M_{23}(B, C)_{6}$, with $\mathrm{M}=$ $\mathrm{Fe}$ or $\mathrm{Cr}$, is the most remarkable microstructural feature in low alloy boron added steels. First reported in 1954, iron borocarbide $\mathrm{Fe}_{23}(\mathrm{~B}, \mathrm{C})_{6}$ presents FCC structure $\left(\mathrm{Cr}_{23} \mathrm{C}_{6}\right.$ prototype) and lattice parameter near $10.6 \AA .^{3 ; 4 ; 5}$ Previous studies have shown that $M_{23}(B, C)_{6}$ borocarbides are not completely dissolved in austenitizing temperatures up to $1000^{\circ} \mathrm{C} .^{6}$ Its orientation relationship with austenite lattice $\{100\}_{\gamma} \|\{100\} M_{23} C_{6}$ leads to low interface energy and delays ferrite nucleation when small borocarbide precipitates are present. ${ }^{7 ; 8}$ The occurrence of large borocarbides $M_{23}(B, C)_{6}$ was reported to promote ferrite nucleation at the interface, explained by loss of coherence and its consequent interfacial energy increase, creating preferred sites for nucleation. ${ }^{9}$

Figure 1 shows a schematic diagram for ferrite nucleation at $M_{23}(B, C)_{6} /$ austenite interface. Hypothetical coherent and incoherent $M_{23}(B, C)_{6}$ boundaries are shown in (a). Ferrite nucleation occurs preferentially at incoherent interface $(b$, c) because its higher interface energy. Ferrite phase may grow up to cover borocarbide particles completely (d). ${ }^{10}$

Studies conducted in HAZ (Heat Affected Zone) of SAE 10B20 steel grade proposed the influence of cooling rate on $M_{23}(B, C)_{6}$ borocarbide precipitation. Generally, higher cooling rates delay (or even suppress) borocarbide precipitation. ${ }^{11 ; 12}$ Massive $M_{23}(B, C)_{6}$ occurrence was reported in SAE 10B22 austenitized at $1000^{\circ} \mathrm{C}$ and cooled at $0.5^{\circ} \mathrm{C} / \mathrm{s}$ and $5^{\circ} \mathrm{C} / \mathrm{s}$.

*e-mail: jp_antunes@ymail.com
In order to achieve cost saving, some automotive suspension and transmission components are made of DIN 39MnCrB6-2 steel grade. Impact tests evaluation of this material is chosen in order to better reproduce possible critical application conditions of these components.

The main objective of this study was to evaluate the influence of initial microstructure and heat treatment (solution; quenching and tempering) in the Charpy V-notch resistance of large scale hot rolled DIN 39MnCrB6-2 steel, correlating the results with the microstructural features observed in the samples.

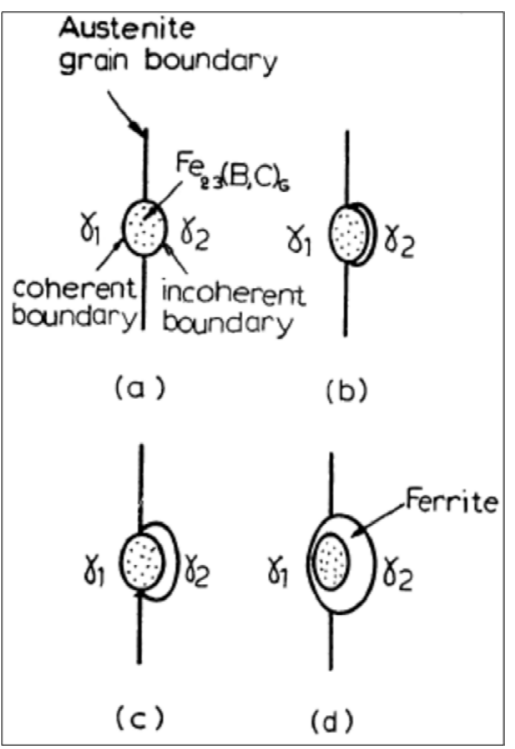

Figure 1. Schematic diagram of ferrite nucleation and growth at $\mathrm{Fe}_{23}(B, C)_{6}$ /austenite interface. ${ }^{9 ; 12}$. 


\section{Experimental Procedure}

The samples for this study were removed from $155 \mathrm{~mm}$ square section bars produced by hot rolling. The chemical composition of the material is given in Table $1 . \mathrm{B}_{\mathrm{S}}$ represents soluble boron which effectively contributes to hardenability (small borocarbide particles at grain boundaries).

Chemical composition from Table 1 was used as input data for thermodynamic simulations, in ThermoCalc $\AA$ software with TCFE7 database. Graphite phase was not used in calculations, allowing formation of cementite. Due to the lack of reports of M2B boride occurrence in steels with low addition of boron, $\mathrm{M} 2 \mathrm{~B}$ phase was not used in calculations as well.

Half sections of rolled bars (Figure 2) were used to extract samples for heat treatments consisting of Solution treatment followed by Quenching and Tempering as indicated in Figure 3. Austenitizing temperature for quenching was $880^{\circ} \mathrm{C}$ based on industrial practices regarding this steel grade.

Solution treatments were carried out in some samples in order to evaluate the influence of prior borocarbide size on CVN toughness. Samples submitted to solution treatment prior to quenching and tempering were identified as $S+Q \& T$ and samples submitted only to quenching and tempering were identified as $Q \& T$. Heat treatment parameters are summarized in Table 2.

After heat treatments, blanks were taken from Surface (S), Mid-thickness (M) and Core (C), as illustrated Figure 2b. The blanks from each position were machined to 3 Charpy V-notch specimens according to ASTM E23 - Type A and tested at room temperature. Surface fracture analysis and phase chemical compositions were performed in a Hitachi ${ }^{\circledR}$ TM3000-TabletopMicroscope with EDS system.

\section{Results}

\subsection{Thermodynamic simulations}

Isopleth section with predicted phases were simulated for the alloy in Table 1 without boron, as shown in Figure 4, and with boron, as shown in Figure 5.

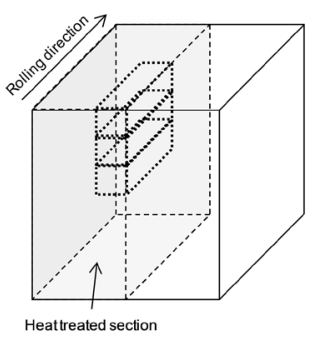

(a)

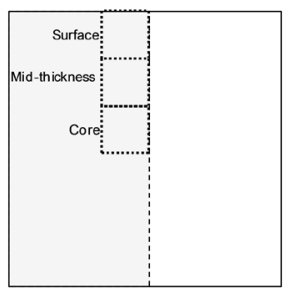

(b)
Figure 2. (a) Schematic diagrams of the blanks and positions where CVN specimens were removed and (b) Cross-section of (a).

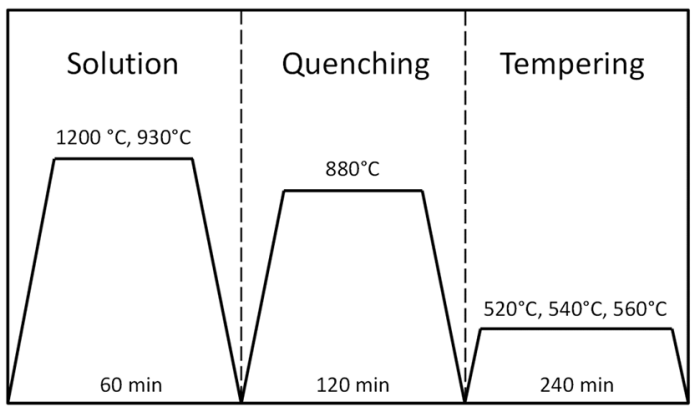

Figure 3. Heat treatment conditions.

It is possible to observe that boron addition significantly changes phase diagram fields. Borocarbides exhibits lower free energy when compared with respective carbides in boron free compound and it results in wider range of stability in boron-containing alloys. Cementite with boron in carbon sublattice, $M_{3}(B, C)$, is more stable than cementite and it is predicted up to $1000^{\circ} \mathrm{C}$. Furthermore, iron carbide $M_{23} C_{6}$ is not stable in boron-free steel and respective borocarbide $M_{23}$ $(B, C)_{6}$ is stable in boron-containing alloy. The $M_{23}(B, C)_{6}$ dissolution temperature is about $900^{\circ} \mathrm{C}$ for alloy with 0.36 wt. \%C.

Predicted volume fraction of phases for alloy with boron content is shown in Figure 6. At $880^{\circ} \mathrm{C}, \gamma$ and $M_{23}(B, C)_{6}$ are predicted in simulated system with volume fractions of $99,9704 \%$ and $0,0296 \%$, respectively.

Table 1. Chemical composition of the steel used in this work, in wt. \%.

\begin{tabular}{ccccccccc}
\hline Element & $\mathbf{C}$ & $\mathbf{S i}$ & $\mathbf{M n}$ & $\mathbf{C r}$ & $\mathbf{N i}$ & $\mathbf{M o}$ & $\mathbf{B s}$ & $\mathbf{F e}$ \\
\hline $\begin{array}{c}\text { Contents } \\
\text { wt.\% }\end{array}$ & 0.36 & 0.34 & 1.56 & 0.59 & 0.04 & 0.05 & 0.0017 & Balance \\
\hline
\end{tabular}

Table 2. Heat treatment parameters.

\begin{tabular}{|c|c|c|c|}
\hline Sample Identification & Solution & Quenching & Tempering \\
\hline$Q \& T_{520}$ & & \multirow{5}{*}{$\begin{array}{c}880^{\circ} \mathrm{C}-120 \mathrm{~min} / \text { Oil- } \\
\text { quenching }\end{array}$} & $520^{\circ} \mathrm{C}-120 \mathrm{~min} /$ Air cooling \\
\hline$Q \& T_{540}$ & - & & $540^{\circ} \mathrm{C}-120 \mathrm{~min} / \mathrm{Air}$ cooling \\
\hline$Q \& T_{560}$ & & & $560^{\circ} \mathrm{C}-120 \mathrm{~min} / \mathrm{Air}$ cooling \\
\hline$S_{1200}+Q \& T_{520}$ & $\begin{array}{c}1200^{\circ} \mathrm{C}-60 \mathrm{~min} / \text { Forced-air } \\
\text { cooling }\end{array}$ & & $520^{\circ} \mathrm{C}-120 \mathrm{~min} /$ Air cooling \\
\hline$S_{930}+Q \& T_{520}$ & $\begin{array}{c}930^{\circ} \mathrm{C}-60 \mathrm{~min} / \text { Forced- air } \\
\text { cooling }\end{array}$ & & $520^{\circ} \mathrm{C}-120 \mathrm{~min} / \mathrm{Air}$ cooling \\
\hline
\end{tabular}




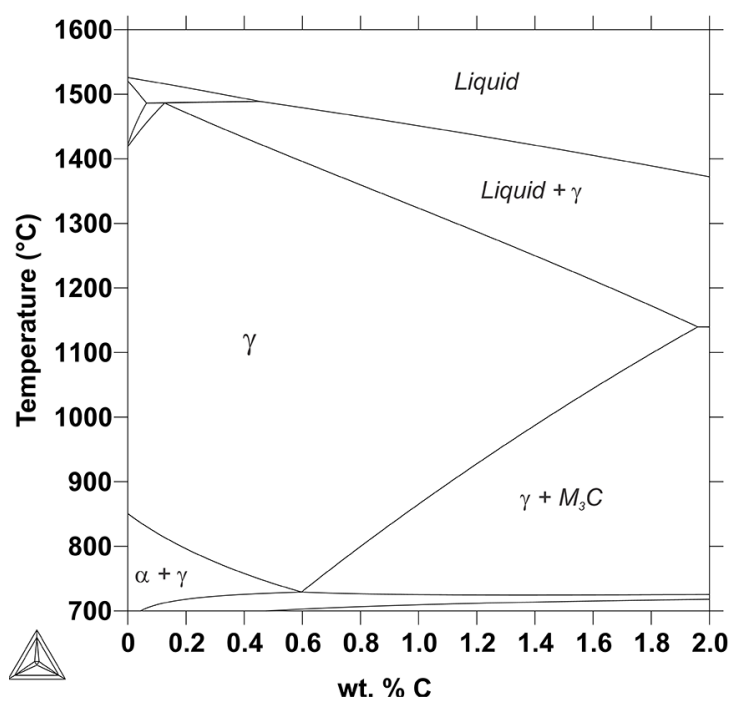

Figure 4. Isopleth for alloy composition from Table 1 without boron.

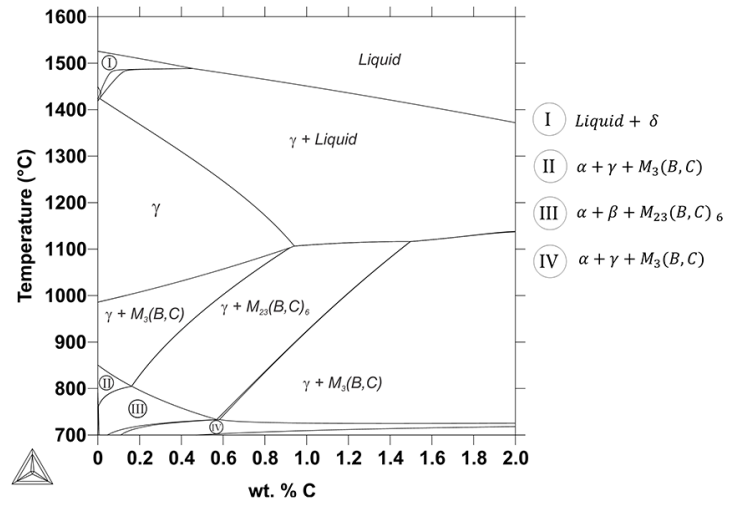

Figure 5. Isopleth simulation of alloy compositions from Table 1.

\subsection{As rolled samples}

SEM analysis of the as-rolled bars have indicated large amount of borocarbide precipitates in the matrix, as shown in Figure 7. Precipitate higher hardness in comparison to matrix is denoted by plastic deformation around the particles. Semi-quantitative EDS analysis proved the existence of carbon and boron in the precipitates, point $\boldsymbol{B}$ in Figure 8.

\subsection{CVN toughness}

For the specimens not submitted to solution treatment, tempering does not seem to affect significantly CVN toughness results. All the specimens reached toughness up to 25-30 J with small standard deviation, as shown in Table 3. However, it has been found a tendency for lower CVN toughness as the distance from the surface increases, as shown in Figure 9. Core specimens presented lower CVN toughness.

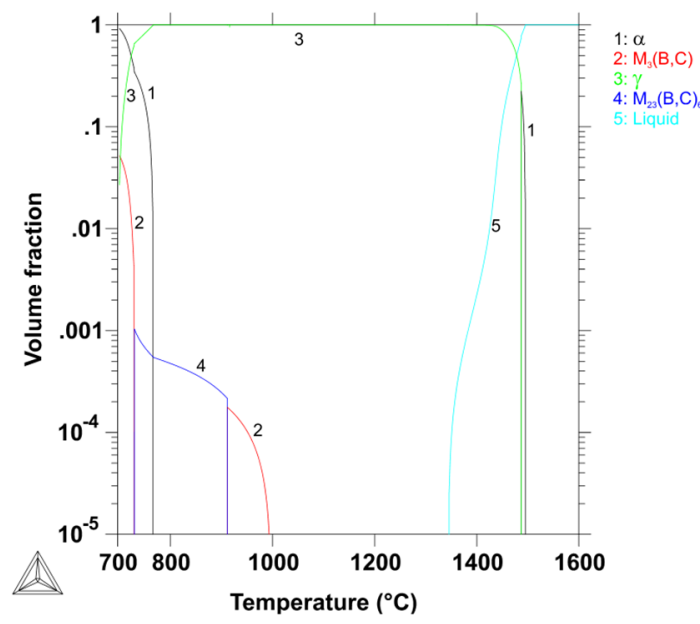

Figure 6. Volume fraction of phases calculated with steel composition from Table 1.

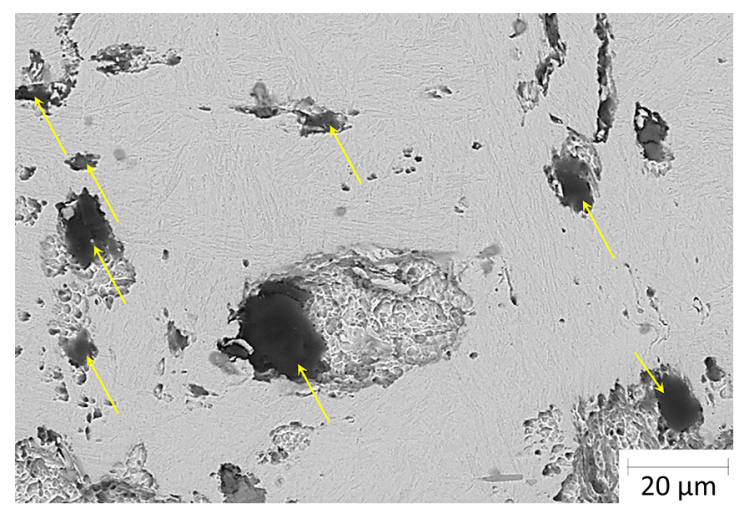

Figure 7. SEM/BSE micrograph indicating large borocarbides precipitates in as-rolled sample.
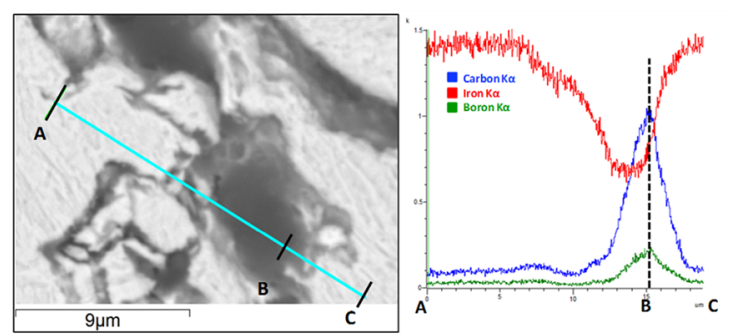

Figure 8. Semi-quantitative compositional analysis via EDS line scan confirming carbon and boron in the dark precipitates from Figure 7.

In order to evaluate effect of tempering temperature in other mechanical properties, hardness was measured on mid-thickness samples and the results are shown in Table 4. Average hardness decreases with increasing tempering temperature but significant difference was obtained only in higher tempering temperature. 
Table 3. CVN toughness results for samples which were not submitted to solution treatment. Average and standard deviation for 3 specimens.

\begin{tabular}{lcccc}
\hline & & \multicolumn{3}{c}{ CVN Toughness (Standard } \\
Deviation) $\boldsymbol{J}$ \\
\cline { 3 - 5 } Sample & $\begin{array}{c}\text { Tempering } \\
{ }^{\circ} \boldsymbol{C}\end{array}$ & Surface & $\begin{array}{c}\text { Mid- } \\
\text { Thickness }\end{array}$ & Core \\
\hline$Q \& T_{520}$ & 520 & $25.5(1.2)$ & $24.5(1.5)$ & $23.5(1.6)$ \\
$Q \& T_{540}$ & 540 & $29.4(2.0)$ & $19.6(2.0)$ & $17.7(1.2)$ \\
$Q \& T_{560}$ & 560 & $29.5(1.2)$ & $19.6(1.9)$ & $19.6(2.1)$ \\
\hline
\end{tabular}

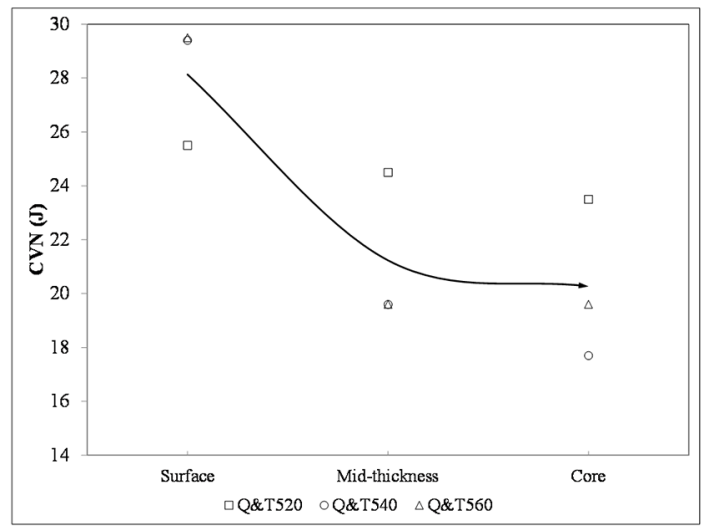

Figure 9. $\mathrm{CVN}$ toughness results for samples quenched and tempered at $520^{\circ} \mathrm{C}(\square), 540^{\circ} \mathrm{C}(\circ)$ and $560^{\circ} \mathrm{C}(\Delta)$.

In agreement with CVN results, SEM analysis of surface fractures have not shown significant differences in microstructures of $Q \& T_{520}, Q \& T_{540}$ and $Q \& T_{560}$ specimens. A SEM fracture micrograph from mid-radius $C V N$ specimen $Q \& T_{520}$ is shown in Figure 10.

It is possible to observe second phase particles with average diameter of $15 \mu \mathrm{m}$ (indicated as $\boldsymbol{A}$ in Figure 10) in $Q \& T_{520}, Q \& T_{540}$ and $Q \& T_{560}$ specimens. Those particles were characterized as iron borocarbides (Figure 11). The occurrence of cracks linked to iron borocarbides particles indicated as $\boldsymbol{B}$ in Figure 10 is a strong evidence that $M_{23}(B$, $C_{6} / \gamma$ interface is the preferred path for crack propagation. It is reasonable to assume that the embrittlement is caused mainly by the occurrence of these coarse borocarbide particles.

The morphology and distribution of borocarbides particles found in Q\&T samples is quite similar to those found in as-rolled sample. This suggests that austenitizing in quenching treatment $\left(880^{\circ} \mathrm{C} / 120 \mathrm{~min}\right)$ was not sufficient to promote their complete dissolution, which agrees with data from thermodynamic simulation shown in Figure 5.

The influence of a previous solution treatment on $\mathrm{CVN}$ toughness results is shown in Figure 12. The main objective of solution treatment was to promote the dissolution of coarse $M_{23}(B, C)_{6}$ borocarbide. Solution treatment at $1200^{\circ} \mathrm{C}$
Table 4. Hardness measurement for mid-thickness samples which were not submitted to solution treatment. Average and standard deviation for 3 indentations.

\begin{tabular}{ccc}
\hline Sample & Tempering $^{\circ} \boldsymbol{C}$ & $\begin{array}{c}\text { Hardness } \\
\text { (Standard } \\
\text { Deviation) } \boldsymbol{H R \boldsymbol { c }}\end{array}$ \\
\hline$Q \& T_{520}$ & 520 & $33.5(0.6)$ \\
$Q \& T_{540}$ & 540 & $33.0(0.5)$ \\
$Q \& T_{560}$ & 560 & $31.2(0.8)$ \\
\hline
\end{tabular}

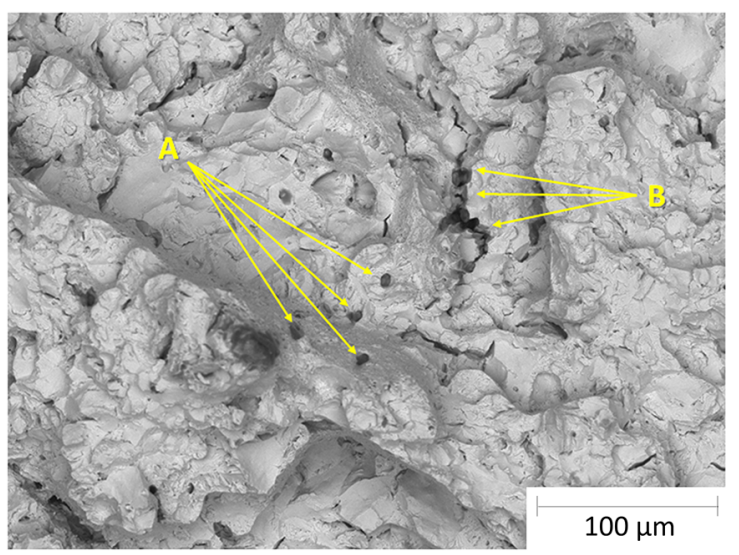

Figure 10. SEM/BSE image of fracture surface from CVN specimen from sample $Q \& T_{520}$. Indication of the large borocarbide particles.

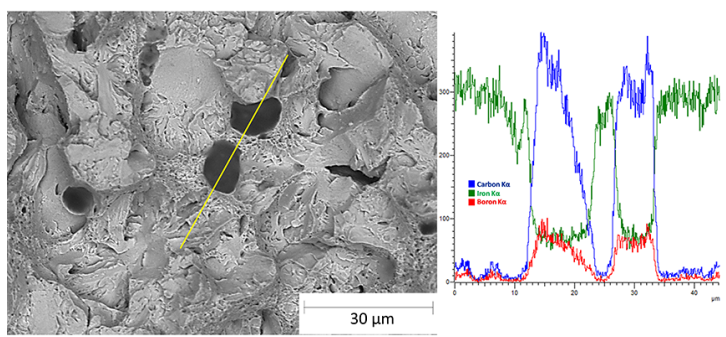

Figure 11. Semi-quantitative compositional analysis of $Q \& T_{520}$ specimen via EDS indicating carbon and boron in precipitate.

decreases CVN toughness because it leads to significantly austenitic grain growth. However, solution treatment at $930^{\circ} \mathrm{C}$ increased $\mathrm{CVN}$ toughness to approximately $50 \mathrm{~J}$. This temperature is high enough to promote $M_{23}(B, C)_{6}$ dissolution and precipitation of small borocarbides particles during cooling. In addition, at this temperature grain growth is not significant.

SEM micrographs from surface fracture of specimens $S_{930}$ $+Q \& T_{520}$ have not shown coarse borocarbides particles, as shown in Figure 13, in agreement with previous discussion. Since fracture main micromechanism is similar in samples submitted to solution treatment and samples without solution treatment, borocarbides occurrence in fracture is the main difference between samples submitted to solution and samples submitted only to quenching and tempering. 


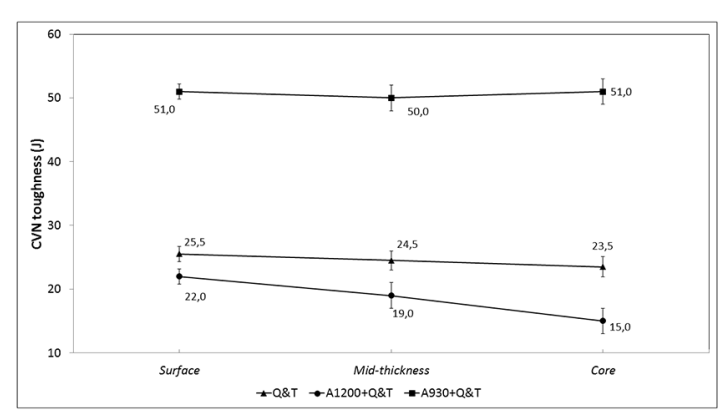

Figure 12. CVN toughness results for specimens quenched and tempered at $520^{\circ} \mathrm{C}$ : without solution $(\boldsymbol{\Delta})$; solution treatment at $1200^{\circ} \mathrm{C}(\bullet)$ and solution treatment at $930^{\circ} \mathrm{C}(\mathbf{\bullet})$.

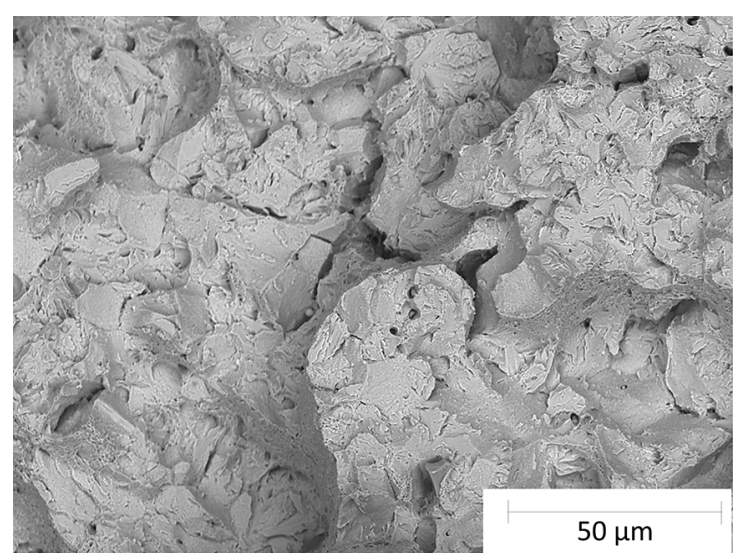

Figure 13. SEM/BSE image of fracture surface from CVN midthickness specimen from sample $\mathrm{S}_{930}+\mathrm{Q} \& \mathrm{~T}_{520}$.

\section{Conclusions}

From the results obtained in this investigation, the following conclusions can be summarized.

1) Small amount of boron significantly changes the equilibrium phase diagram of steel DIN 39MnCrB6-2, allowing formation of $M_{23}(B, C)_{6}$ borocarbide;

2) Austenitizing temperature of $880^{\circ} \mathrm{C}$ did not promote complete dissolution of coarse $M_{23}(B$, C) ${ }_{6}$ borocarbides;

3) The presence of large borocarbides leads to low CVN toughness;

4) In samples submitted to solution treatment at $930^{\circ} \mathrm{C}$, higher $\mathrm{CVN}$ values were obtained. Charpy impact fracture analyses have not shown large borocarbides, indicating a change in crack propagation path, which can be explained by partial dissolution of borocarbides at $930^{\circ} \mathrm{C}$.

\section{References}

1. Taylor KA. Grain-boundary segregation and precipitation of boron in 0.2 percent carbon steels. Metallurgical Transactions A. 1992;23(1):107-119.

2. Mun DJ, Shin EJ, Koo YM. A study of the behaviour of boron distribution in low carbon steel by particle tracking autoradiography. Nuclear Engineering and Technology. 2011;43(1):1-6.

3. Casarin SJ. Caracterização da temperabilidade de um aço C-Mn microligado ao boro, através de dilatometria e curvas de transformações de fases por resfriamento contínuo [Tese]. São Carlos: Universidade de São Carlos; 1996. 181 p.

4. Carroll KG, Darken LS, Filer EW, Zwell L. A New Iron BoroCarbide. Nature. 1954;174:978-979.

5. Maitrepierre P, Rofes-Vernis J. Thivellier D. Structure- properties relationships in boron steels. In: Boron in steel: proceedings of the International Symposium on Boron Steels; 1979 Sep 18; Milwaukee, WI, USA.

6. Djahazi M. Influence of boron distribution on precipitation and recrystallization in hot worked austenite. [Thesis]. Montreal: Department of Mining and Metallurgical Engineering - McGill University; 1989.

7. Beckitt FR, Clark BR. The shape and mechanism of formation of $\mathrm{M}_{23} \mathrm{C}_{6}$ carbide in austenite. Acta Metallurgica. 1967;15(1):113129 .

8. Singhal LK, Martin JW. The growth of $\mathrm{M}_{23} \mathrm{C}_{6}$ carbide on incoherent twin boundaries in austenite. Acta Metallurgica. 1967;15(10):1603-1610.

9. Morral JE, Cameron TB. Boron hardenability mechanisms. In: Boron in steel: proceedings of the International Symposium on Boron Steels; 1979 Sep 18; Milwaukee, WI, USA.

10. Mavropoulos LT. The synergistic effect of niobium and boron on recrystallization in hot worked austenite [Thesis]. Department of Mining and Metallurgical Engineering, McGill University; 1986.

11. Devletian JH. Borocarbide Precipitation in the HAZ of Boron Steel Welds. Welding Research Supplement. 1976;55:5s-12s.

12. Devletian JH, Heine RW. Effect of Boron Content on Carbon Steel Welds. Welding Research Supplement. 1975(2):45-53. 